Article

\title{
Is the China-Pakistan Economic Corridor an Opportunity or a Threat for Small and Micro-Entrepreneurs? Empirical Evidence from Northern Pakistan
}

\author{
Saranjam Baig ${ }^{1,2, * \mathbb{C}}$, Mir Qasim ${ }^{1}$, Li Xuemei ${ }^{3, *}$ and Khalid Mehmood Alam ${ }^{1,3}$ \\ 1 Center for Research on China-Pakistan Economic Corridor, Karakoram International University, \\ Gilgit 15100, Pakistan; mrqasim3@gmail.com (M.Q.); khalid@bjtu.edu.cn (K.M.A.) \\ 2 College of Economics and Political Science, Sultan Qaboos University, Muscat, Al-Khoud 123, Oman \\ 3 School of Economics and Management, Beijing Jiaotong University, Beijing 100044, China \\ * Correspondence: saranjam.baig@alumni.cgu.edu (S.B.); xmli@bjtu.edu.cn (L.X.); \\ Tel.: +92-5811-960937 (S.B.); +86-10-5168-4238 (L.X.)
}

Received: 6 February 2020; Accepted: 20 February 2020; Published: 25 February 2020

check for updates

\begin{abstract}
Are the mega-projects an opportunity or threat for micro and small firms? This question has rarely been examined in the literature. Micro and Small Enterprises (MSEs) have always been at the forefront, playing an important role in the development of rural economies in developing countries like Pakistan. Since the China-Pakistan Economic Corridor (CPEC) project has been initiated, northern Pakistan (Gilgit-Baltistan) has witnessed a huge tourist inflow. As a result, the mushrooming of businesses along the CPEC route is a new phenomenon. The increasing trends in tourism inflow on one side offer new opportunities for MSEs while, on the other side, it increases the competition level among the firms. In the background, this research aims at contributing to existing academic scholarship on whether increasing competition is healthy for the growth and sustainability of MSEs or it might challenge their future progress. To examine this question, we carried out field surveys. Through questionnaires, we collected data for 280 micro and small firms operating in the tourism sector along the CPEC route. The study investigates current and future prospects of micro and small enterprises in the region, given that the CPEC is fostering tourism, which has its effects on the allied industries as well. The study relies on the Jovanovic (1982) model of firm growth and theory of market participation for its theoretical foundation and uses a logistic regression model as the estimation strategy. The findings suggest that the CPEC is not the only opportunity for tourism-related micro and small enterprises but also helpful for the growth of medium and large firms. The implications are that if MSEs could not prepare themselves to compete, there is a chance that medium and large firms would replace them. Growth of MSEs is conditional on easy access to finance and borrowings.
\end{abstract}

Keywords: CPEC; tourism; micro-entrepreneurs; small enterprises; sustainability; Gilgit-Baltistan

\section{Introduction}

Are the mega-projects an opportunity or threat for micro and small firms? This question is rarely examined in the literature. This study is specifically focusing on filling the gap of whether mega-projects like economic corridors enhance or squeeze the opportunities for micro and small firms. To analyze the impact of the mega project on the performance of micro and small enterprises (MSEs), we are taking the case study of the China-Pakistan Economic Corridor (CPEC), which is a multi-billion investment project in Pakistan under China's Belt and Road Initiative (BRI). While examining the impact of a transport infrastructure project on various socio-economic dimensions, Korytarova et al. [1] 
emphasized monitoring the impact of mega-projects on their surroundings. Huge investments in infrastructure, power, and communication under the CPEC has made northern Pakistan relatively accessible for tourists. Therefore, the inflow of tourists to the region has increased. Whether this CPEC-fostered tourism is a harbinger of new opportunities for micro-entrepreneurs, or a threat, is yet to be examined, and this research aims at investigating this relationship.

Fast-growing micro and small enterprises (MSEs) are considered important for the economic growth of less developed economies [2]. In some cases, the rapid growth becomes a hurdle that makes MSEs less potential to sustain in the market. For instance, an increase in market competition in the tourism industry provides an opportunity for large firms to dominate it by making small firms out of business. Kirsten and Rogerson [3] argue that large firms are dominating the market in developing countries that marginalize small firms in the tourism sector. Other than that, many small firms do not have proper planning and lack management skills. Some firms do not have resources and time to execute and implement plans and follow them in an efficient manner [4]. Many studies have suggested multiple factors that are responsible for the growth and survival of small firms. The growth and survival of a small business is explained by the ability and skill of entrepreneurs and 'learning by doing' of the firm $[5,6]$.

Gilgit-Baltistan, the northern mountainous region of Pakistan, is famous for its tourism worldwide. Currently, the region is experiencing rapid tourism growth [7] due to investments under the CPEC, China's flagship mega-project of Belt and Road Initiative (BRI) [8]. The economic corridor that links Pakistan to China via Karakoram Highway (KKH, the old silk route) has resulted in peace restoration, infrastructure development, and better connectivity and communication $[9,10]$. The mega project has the potential to bring economic opportunities to Pakistan and can enhance regional and cross regional economic and trade relations between Central Asia, South Asia, East and West Asia [11].

Tourism, being an important industry, has huge potential to boost up micro and small enterprises. As a strategy for poverty alleviation for poverty-stricken nations, tourism growth is currently gaining attention [12]. Likewise, in Gilgit-Baltistan, tourism is one of the important sectors providing business and employment opportunities to the inhabitants. According to one study, the share of tourism in GDP remained 2.9\% in 2016 and 5.9\% in 2017 in Pakistan, where tourism investment remained 9.1\% of total investment in 2016 [13]. These figures suggest that Pakistan's tourism industry still has unexplored potential.

The tourism industry offers not only remarkable opportunities for medium and large firms but also provides greater opportunities to MSE's. That's why the participation of micro and small firms in the tourism sector has increased. Mulhern [14] observes that small business enterprises are not only beneficial to economic progress and prosperity in western free-market economies, but they have also served as a vital engine of employment growth of less developed economies. The role of microenterprises is not hidden for the robust growth of the economy because it accelerates economic development by providing space for unemployed men and women in rural areas. Many studies have highlighted the role of micro and small enterprises in economic development [15-17].

The argument we are making in this study is that due to the expansion of current economic activities under the CPEC, especially the exponential growth in tourists' inflow [18], the opportunities for expansion, as well as competition among micro and small businesses, is rapidly increasing. The trend of increasing tourism flow to the region is presented in Figure 1. The increase of tourist inflow after 2014 indicates the impact of the CPEC on the tourism sector in the region. With this in the backdrop, the current study aims at analyzing the effect of the CPEC on Micro and Small Enterprises (MSEs) in the tourism sector of Gilgit-Baltistan along the alignment of the CPEC route.

Since the CPEC was initiated, researchers argue that it will provide enormous opportunities for the business sector in Pakistan [19]. Modernized infrastructure, sustainable peace, and increasing level of energy production are the lifeblood for businesses where the CPEC is providing a colossal platform for investors to capture the remarkable business opportunities for firms. Ali et al. [20] see the CPEC as a very handsome package that can contribute many areas, especially development of infrastructure, 
solving energy crises and communication systems, increase in employment opportunities, and overall economic revival [21]. Such a supporting environment is grace for businesses. Along with the benefits, there are some major challenges for MSEs' sustainability.

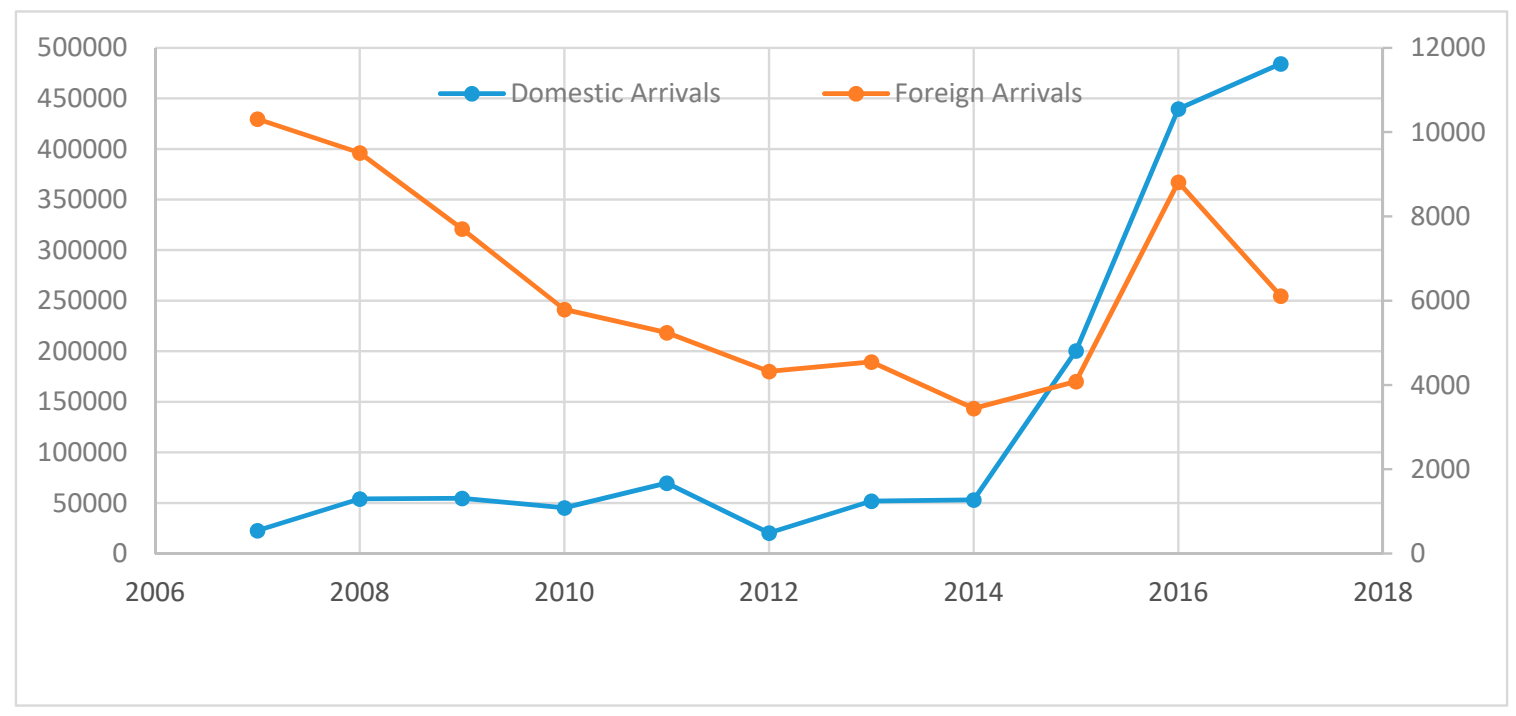

Figure 1. Tourist arrivals. Source: Department of Tourism, Government of Gilgit-Baltistan.

\section{Growth and Sustainability of MSEs in the Context of the CPEC Fostered Tourism in GB}

In today's world, many nations have put their attention to the private sector, particularly on MSEs, due to their prominent role in economic development and job creation [22]. Measuring the performance of a micro and small enterprise is complex and multi-dimensional in nature because it depends on various internal and external components of MSEs'. Mostly it depends on motivations of the owner and manager, goals and capabilities, internal factors, infrastructure, regional specific resources, and external relationships [23-25]. In a small enterprise, entrepreneurs' role is very crucial for the effective growth and progress of the firm. In small firms, one key decision-maker typically controls the ownership and capital and is powerfully influential on the decisions and objectives of firms [26].

The China-Pakistan Economic Corridor (CPEC) is a pioneer project of the Belt and Road Initiative, where China has planned to interlink global communities through road and railway networks $[27,28]$. The project passes through $300 \mathrm{~km}$ from Gilgit-Baltistan (GB), northern Pakistan. Researchers and policymakers consider the corridor as a game-changing project for both China and Pakistan [9,29]. Resultantly, because of improved infrastructure and communications, and stability under the CPEC, GB has been witnessing an increasing trend of tourist inflow. The development of tourism is closely related to the construction of infrastructure because the tourist generally chooses the form of tourism traffic according to the conditions of local travel needs like roads, rail aviation, and water, etc., [30].

The fast-growing tourism industry is inevitable for regional economies. The tourism sector is considered to be the largest industry and job creator in the world [31], and the same is true in the case of GB, where the largest portion of the labor force is absorbed in the businesses within the tourism industry. Tourism provides a wide range of opportunities for both foreign and local entrepreneurs while it also brings investment, foreign exchange earnings, and the creation of micro small and medium enterprises [32]. The opportunities that accompany mega-projects, such as the increase in tourists' inflow, sometimes may become a threat for different sectors if proper policies are not formulated to cope with the challenges faced by various segments in the society. In the current study, we are keen to explore whether the CPEC is always an opportunity for micro and small enterprises or if it can be a threat for MSEs in the long run. 
After the CPEC-related investments in infrastructure and communications, tourism inflow to GB has increased [7]. Thus, competition level among micro and small enterprises has increased as many new firms enter into the tourism market. As Ahmad et al. [33] suggest that because of economic globalization and liberalization, firms understand the intense competition they face: they need to diversify risk in order to achieve economies of scope and scale. Tourism has the potential to stimulate local businesses, and, in this way, the sector potentially contributes to regional economic development [34-36]. It is considered an opportunity in the sense that the growing level of demand increases the level of sale and profitability of firms only if firms manage and utilize all its resources well according to the situation and preferences of customers. On the other hand, if firms cannot manage their resources properly, they have to face tough competition. Hence, the chances of sustainability become bleak, while the persistent growth of firms would not be expected.

The rest of the paper is structured in the following order. Section 2 provides a literature review. Section 3 presents the theoretical background followed by the section on materials and methods. Section 5 provides results and discussion, and Section 6 concludes this study.

\section{Literature Review}

Limited research is available on the relationships between mega-projects and MSEs in the tourism sector due to the paucity of primary and secondary data and by the challenges that the diversity of micro, and small firms present [37]. As many rural areas rely on tourism to sustain their economies, the business sector may consist of many tourism-focused MSEs (TMSE). The small size of population, distance, and lack of proper infrastructure makes large enterprises less viable to operate in rural regions. Whereas, because of the perceived benefits to the community's quality of life and the potentially low environmental impact, smaller rural communities favor TMSEs for their economic development [38]. Tourism literature indicates the fact that growth in the tourism industry has the potential to stimulate economic growth and development. Having the importance of businesses, little focus has been paid to entrepreneurial activity, specifically on how small tourism firms are operating in developing economies.

However, the definitions of MSE always remained a major concern in the literature. Different researchers have defined MSEs in terms of size, capital asset, and capital turnover for different countries. The Bolton committee first formulated the economic and statistical definition [39]. According to them, a firm is said to be small when; (1) it has a relatively small share of their marketplace; (2) it is managed by owners or part-owners in a personalized way, and not through the medium of a formalized management structure; (3) it is independent, in the sense of not forming part of a large enterprise. Likewise, Morrison [40] defines the small business in tourism as "business financed by one individual or small group, directly managed by its owner(s). It is perceived small in terms of physical facilities, production/service facility market share and several employees".

In the contemporary world, the role of MSE in different sectors is increasing day by day. Tourism is one of the most conspicuous sectors that provides enormous opportunities for small firms, their growth, expansion, and progress. Besides opportunities, various perceived challenges are always there, which are alarming for their future progress and sustainability, while less attention is being paid in the literature to capture this emerging issue. Fuller et al. [41] investigate the challenges of the indigenous community in northern Australia and argue that tourism has the potential to overcome the challenge through effective tourism enterprises or micro-businesses, which often have some competitive advantages. Through 'Strengths, Weaknesses, Opportunities, and Threats' SWOT analysis, the study also presents the huge failure rate of small businesses and argues that proper planning is required in this regard. The study suggests that partnerships with other stakeholders within the region can help to overcome this constraint.

For a long time, the growth and survival of the small firms has always remained the point of concentration for researchers. For instance, Nichter et al. [42] studied the different factors that are responsible for the growth of small firms in developing countries. The study discusses four major factors that are: individual and entrepreneur's characteristics, firm characteristics, relational factors, 
and business environment, while Islam et al. [43] attempted to investigate various macro and micro factors responsible for the growth and development of MSEs in the case of Bangladesh. Different factors such as education, training facilities, risk orientation, and hard work are witnessed as factors of success for entrepreneurs. While some other socio-economic factors such as commercial law, limited regulation, corruption, support by society, credit facilities, social status and integration, free trade with limited tariffs enterprise zone, strong telecommunication, and distribution networks have been considered important for creating an enterprise.

Akbaba [44] explores the understanding of small tourism businesses by taking Ackokoca Turkey as a case study. The study gives specific attention to the characteristics of business, marketing, finance, human resource management, and involvement of management in the industry and small tourism businesses. The study uses a comparative research methodology using a survey instrument. The findings of the study suggest that small tourism businesses carry significant deficiencies, inadequacies, and face a common set of problems. Different countries have implemented various programs to improve the performance of micro and small enterprises. That is why owners/managers need to be aware of the government's implemented programs or projects. For instance, Maleka et al. [45] examined the role of the South African government regarding the development of MSEs. Through the survey method, the study collects data from the owners of micro-enterprises and investigates the level of awareness about the different governmental support programs. The findings suggest that majority of the owners of micro-enterprises were not aware of the governmental support programs. Likewise, Rogerson [17] investigates the promotion of tourism projects in South Africa by considering special development initiatives' importance for the small and micro-enterprise. The study argues that entrepreneurship within tourism in South Africa can learn from the MSE's experience from the developing world. Whereas, Ateljevic [46] examines the issues related to small business firms. Through 317 firm surveys and 57 in-depth interviews in various localities of New Zealand, the study suggests that the development of small businesses depends on the different factors related to the business owners/manager, nature of tourism activity and its locality, and business environment. While Booyens et al. [15], in their paper, studied the increasing trend of tourism and its economic benefits in the town of Parys, South Africa. The study mainly focuses on the factors that cause fluctuations and create major opportunities and challenges in the sector. The findings recommend comprehensive policy and planning for the future development of industry-focused attractions and identification of key market segments.

In another study, Mead et al. [16] examined the magnitude and determinants of enterprise birth, expansion, and closure. The study explores the ways and different sources of change influenced by the state of the macroeconomy and recommends policy for MSE's role in macroeconomy. McPherson et al. [47] presented how MSEs grow over time. Taking the data of five African countries, their study examines the dynamics of small firms. For instance, the levels of human capital embodied in the proprietor, sector of business, firm location, and gender of proprietors were found to be the important determinants of growth. The result of the study suggested that an inverse relationship exists between the growth of the firm and its age and size.

While focusing on the performance of enterprises in the tourism sector, Haber et al. [48] identify performance measures of small ventures through a conceptual model. Using data from 305 small tourism venture owners' through interviews, the findings show that mapping the venture's achievements, developing managerial skills, and allocating resources cause to improve the performance and chances of survival in the long run. Basu et al. [49] investigated the factors influencing the South Asian entrepreneurial growth in Britain. The study develops a multivariate model and estimates it by considering small business economic and cultural variables. The theoretical model assumes cultural factors have an augmented effect on socio-economic factors. The result shows that moving away from the style of management based on immigrant culture has a positive effect on growth. Furthermore, the study reveals that strengthening links with the country of origin has a positive impact on growth. Also, the characteristics of business and enterprise are more crucial than financial resources in contributing 
to growth. In a similar study, Bouazza et al. [22] analyzed the factors affecting the growth rate of small and medium-sized enterprises in Algeria. The study considers different internal and external factors responsible for the unstable low growth of small and medium-sized enterprises. The study considers a business environment that is under the control of small and medium-sized enterprises (SMEs) as internal, and factors like legal framework, access to financing, and human resource capacities are considered as external. They highlight multiple challenges for SMEs in Algeria. They suggest that challenges arise from the interaction of internal and external factors.

\section{Theoretical Background}

Around the world, while some new firms are being birthed, some others are getting closed. Likewise, various existing enterprises are expanding, whereas few are contracting in volume and size. Why do some micro and small enterprises grow faster while others do not? What factors are behind faster growth, and why do some firms survive for many years? Particularly in the case of developing countries, no theory has been developed yet. Despite that, it will be very useful to review the existing theories behind firm growth and survival and to point out the appropriate theory for MSE's.

Jovanovic [5] presented a model of MSE growth, which considers the measurement ability and risk as a determinant of MSE growth. However, the model does not contemplate some of the specific variables that are very decisive for the firm's growth, e.g., location of the business, the gender of entrepreneur/owner, sub-sector of business. Another strand of literature, on the other hand, suggests multiple factors for the growth and stability of small firms where firm age, size, and location is closely reflected [50-52]. The dynamics behind the churning and growth of MSE is examined by many researchers. Mead et al. [16] extensively argued the dynamics of growth and survival of MSEs'. The study identified the size of the enterprise, characteristics of labors and owners, location of the business, the gender of entrepreneurs, the efficiency of firms as a major determinant of expansion and closure of firms. The increasing competition level is one of the important factors that can cause the growth of MSEs, but existing studies do not consider its impact on a firm's performance, which may further lead to the expansion/closure of small firms. Better progress and growth of the firm have always been dependent on the huge potential of the market demand, where it operates and competes. MSEs have their attributes and characteristics, which are considered in determining their performance. The dynamic and innovative world continuously offers new ways and methods, which are paramount for the smooth functioning of micro and small businesses.

\section{Materials and Methods}

\subsection{Sampling}

The study uses quantitative data collected through questionnaires from micro and small enterprises operating in the tourism sector along the CPEC route in Gilgit-Baltistan. Simple and systematic random sampling is used for data collection. A total of 350 micro and small firms were surveyed in four districts (Eight Tehsils). A total of 280 questionnaires have been used in the study because the data of seventy questionnaires were incomplete. The total population is unknown because almost ninety percent of firms operate in the informal sector. Data from different types of firms have been taken randomly.

According to our survey, there are 250 small villages on the CPEC route in GB, while the total number of MSEs operating on these villages are unknown. Hence, to tackle this problem, we did a scanning survey in five major villages on the route and found out the total MSEs operating there. The results of the survey reveal that, on average, ten MSEs are located in those five villages. Considering the survey information, we generalized this average value to all the remaining villages and got the total number of (population) MSEs $(10 \times 250)=2500$.

To get the exact sample size from the perceived population, we refer to the sample calculation table, which suggested 300 samples for micro enterprises and 50 samples for villages. For taking data from the targeted sample for (MSEs), we used a systematic sampling method for village selection (N/n) 
$250 / 50=5$ (every 5 th village). The data from 50 small villages in four major districts of Hunza, Nagar, Gilgit, and Chilas was taken, and 350 small firms from a total of fifty villages village were randomly selected. Table 1 shows the sampling strategy of the current study.

Table 1. Sampling strategy.

\begin{tabular}{|c|c|c|c|c|c|}
\hline & $\begin{array}{c}\text { Total } \\
\text { Population }\end{array}$ & $\begin{array}{c}\text { Total } \\
\text { Sample }\end{array}$ & $\begin{array}{l}\text { Sampling } \\
\text { Method }\end{array}$ & Formula of Selection & Location \\
\hline Villages & 250 & 50 & $\begin{array}{l}\text { Systematic } \\
\text { random }\end{array}$ & $250 / 50=5$ th village Taken & $\begin{array}{l}\mathrm{CPEC} \\
\text { route }\end{array}$ \\
\hline MSEs & $\begin{array}{c}2500(10 \times 250) \\
\quad=2500\end{array}$ & 280 & Simple random & $\begin{array}{l}\text { Randomly selected MSE's } \\
\text { in every } 5 \text { th village }\end{array}$ & $\begin{array}{l}\mathrm{CPEC} \\
\text { route }\end{array}$ \\
\hline
\end{tabular}

\subsection{Research Instrument}

A questionnaire was designed using unbiased, straight, and simple words considering the level of understanding of the entrepreneurs so that they could easily provide reality-based responses according to their perceptions. A detailed questionnaire was designed according to the requirements of the existing study. A five-point Likert scale was used, ranging from 1 to 5 (strongly disagree to strongly agree), in the questionnaire for the independent variables. The growth of sales, profit, employment, turnover capital, and the current and previous worth of business are considered to gauge the growth status in this analysis, while growth of employees was used to define the dependent variable. These growth components reveal the performance of MSE's growth before and after the CPEC project. Before conducting a proper survey, the pilot test was carried out by taking 60 firms in the Gilgit district to check the validity and reliability of data. Cronbach alpha gave us the validity and reliability of indicators. The result of Cronbach's alpha is given in Table 2.

Table 2. Cronbach's Alpha.

\begin{tabular}{cccc}
\hline S.No & Factors & Items & Cronbach Alpha \\
\hline 1 & Overall Questionnaire & 103 & 0.778 \\
2 & CPEC, opportunity for MSEs & 28 & 0.513 \\
3 & CPEC, threat for MSEs & 22 & 0.591 \\
4 & CPEC and gender enterprises & 13 & 0.883 \\
5 & Binary outcome questions & 10 & 0.915 \\
\hline
\end{tabular}

\subsection{Descriptive Statistics}

Profile of MSEs and Respondents

Table 3 presents the demographic profile of owners, and Table 4 presents the profile of business enterprises. The study data consists of 280 MSEs; out of these, 224 were operational on the CPEC route while 46 were otherwise.

The largest portion of data was taken from general stores and hotels that include $28 \%$ and $18 \%$, respectively, while $11 \%$ of data were taken from the shops selling local items and $4 \%$ from embroidery shops. We collected 39\% of the data from the Gilgit district, 37\% from the Hunza district, $11 \%$ from the Nagar district, and $11 \%$ from the Chilas district.

The data were collected from four major districts of Gilgit on the CPEC route. Tables 3 and 4 display the information of business owners and business enterprises, respectively. During the survey, we got the data from MSEs with different age groups, as presented in Table 4, which shows seventy to eighty percent of firms were more than two years of age and have the experience of the impact of the CPEC on a firm's performances. Furthermore, out of the total firms, $83 \%$ are operating on the route of a mega project. From the table, it indicates that $78 \%$ of owners consider that less than four employees are sufficient for their firm. In addition to that, $86 \%$ of the owners consider that after the mega project of the CPEC, their firm has witnessed $60 \%-70 \%$ growth in terms of daily sales. 
In the case of the demographic profile of business owners, which is presented in Table 3, it shows that $89 \%$ of owners are male, while $11 \%$ of owners are female, depicting the male-dominant society. Out of these owners, $42 \%$ percent were between the age of 15 and 30, $41 \%$ between the age of 30 and $45,14 \%$ between the age of 45 and 60 , and only $3 \%$ were between the age of 60 and 75 . This indicates that mostly the young generation is inclined towards MSEs. On the other hand, $36 \%$ of owners were single, while $64 \%$ were married. Among the owners, only $13 \%$ of employers are illiterate. Overall, the literacy rate among the owners was around $87 \%$.

Table 3. Sample profile of business owners.

\begin{tabular}{|c|c|c|c|}
\hline Particulars & Sampling Dist. & Freq. & Percentage \\
\hline \multirow{5}{*}{ Age } & $15-30$ & 118 & 42.1 \\
\hline & $30-45$ & 116 & 41.4 \\
\hline & $45-60$ & 38 & 13.6 \\
\hline & $60-75$ & 08 & 2.9 \\
\hline & Total & 280 & 100 \\
\hline \multirow{3}{*}{ Gender } & Male & 251 & 89.6 \\
\hline & Female & 29 & 10.4 \\
\hline & Total & 280 & 100 \\
\hline \multirow{3}{*}{ Marital Status } & Single & 111 & 36.6 \\
\hline & Married & 169 & 64.4 \\
\hline & Total & 280 & 100 \\
\hline \multirow{3}{*}{ Family Status } & Nuclear & 93 & 33.2 \\
\hline & Joint & 187 & 66.8 \\
\hline & Total & 280 & 100 \\
\hline \multirow{8}{*}{ Education } & Illiterate & 36 & 12.9 \\
\hline & Primary & 18 & 6.4 \\
\hline & Middle & 40 & 14.3 \\
\hline & High & 53 & 18.9 \\
\hline & Intermediate & 60 & 21.4 \\
\hline & Graduation & 50 & 17.9 \\
\hline & Master & 23 & 8.2 \\
\hline & Total & 280 & 100 \\
\hline \multirow{9}{*}{ District } & Gilgit & 82 & 29.3 \\
\hline & Hunza & 106 & 37.9 \\
\hline & Nagar & 46 & 16.4 \\
\hline & Diamer & 28 & 10.0 \\
\hline & Ghizer & 3 & 1.1 \\
\hline & Astore & 3 & 1.1 \\
\hline & Skardu & 2 & 0.7 \\
\hline & Other & 10 & 3.6 \\
\hline & Total & 280 & 100 \\
\hline \multirow{4}{*}{ Sect } & Sunni & 70 & 25.0 \\
\hline & Shia & 98 & 35.0 \\
\hline & Ismaili & 111 & 39.6 \\
\hline & Total & 280 & 100 \\
\hline
\end{tabular}


Table 4. Sample profile of business enterprises.

\begin{tabular}{|c|c|c|c|}
\hline Particulars & Sampling Dist. & Freq. & Percentage \\
\hline \multirow{7}{*}{ Age } & Below-2 & 31 & 11.1 \\
\hline & $02-04$ & 77 & 27.5 \\
\hline & $04-06$ & 56 & 20.0 \\
\hline & $06-08$ & 28 & 10.0 \\
\hline & $08-10$ & 21 & 7.5 \\
\hline & 10-above & 67 & 23.9 \\
\hline & Total & 280 & 100 \\
\hline \multirow{3}{*}{ Location on CPEC route } & Yes & 224 & 83.6 \\
\hline & No & 46 & 16.4 \\
\hline & Total & 280 & 100 \\
\hline \multirow{8}{*}{ Location } & Gilgit & 57 & 20.4 \\
\hline & Danyore & 29 & 10.4 \\
\hline & Hunza & 86 & 30.7 \\
\hline & Gojal & 17 & 6.07 \\
\hline & Juglot & 27 & 9.6 \\
\hline & Nagar & 32 & 11.4 \\
\hline & Chilas & 32 & 11.4 \\
\hline & Total & 280 & 100 \\
\hline \multirow{9}{*}{ Type } & Hoteling & 53 & 18.9 \\
\hline & Transportation & 16 & 5.7 \\
\hline & General store & 77 & 27.5 \\
\hline & Embroidery & 10 & 3.6 \\
\hline & Tour opp. & 5 & 1.8 \\
\hline & Cultural items & 31 & 11.1 \\
\hline & Homemaking & 16 & 5.7 \\
\hline & Other & 72 & 25.7 \\
\hline & Total & 280 & 100 \\
\hline \multirow{6}{*}{$\begin{array}{c}\text { After CPEC average } \\
\text { daily sale is increased by }\end{array}$} & Below-20\% & 21 & 7.5 \\
\hline & $20 \%-40 \%$ & 92 & 32.9 \\
\hline & $40 \%-60 \%$ & 109 & 38.9 \\
\hline & $60 \%-80 \%$ & 28 & 10.0 \\
\hline & $80 \%-100 \%$ & 05 & 1.80 \\
\hline & Total & 280 & 100 \\
\hline \multirow{6}{*}{$\begin{array}{l}\text { Sufficient workers for } \\
\text { MSEs in GB }\end{array}$} & Below-2 & 142 & 50.7 \\
\hline & $2-4$ & 78 & 27.9 \\
\hline & $4-6$ & 31 & 11.1 \\
\hline & $6-8$ & 17 & 6.1 \\
\hline & 8-above & 12 & 4.3 \\
\hline & Total & 280 & 100 \\
\hline
\end{tabular}

Table 5 shows the position of firms' growth in various factors. Different studies usually consider growth in sales, profit, and employment as the indicators of the growth status of firms. In addition to these, this study considers some other major factors that we consider important to assess the growth of firms. Table 5 presents the change in worth of business, change in the level of skill, manager and employee training, and total time spent in business by the owner. This change is calculated by taking the difference between the current position of the business and the position when the firm was initiated. More than 70\% of enterprises that were surveyed had been operating before the CPEC route. Comparing mean values suggest that each component has changed positively, while the profit and sale have witnessed a huge change. In addition, these positive changes also confirm that the CPEC project is an opportunity for micro enterprises in northern Pakistan. 
Table 5. Descriptive statistics of current and initial status of Micro and Small Enterprises (MSEs).

\begin{tabular}{cccccccccc}
\hline $\mathbf{N}=\mathbf{2 8 0}$ & \multicolumn{4}{c}{ Current (C) } & \multicolumn{3}{c}{ Initial (I) } & Mean Difference \\
\hline Component & Min & Max & Mean & Variance & Min & Max & Mean & Variance & (C-I) \\
\hline Workers & 1 & 6 & 1.74 & $1.03 h$ & 1 & 6 & 1.46 & 1.11 & 0.28 \\
Sale & 1 & 6 & 5.55 & 1.13 & 1 & 6 & 4.38 & 2.68 & 1.17 \\
Profit & 1 & 6 & 4.45 & 2.03 & 1 & 6 & 3.06 & 3.25 & 1.39 \\
Worth & 1 & 5 & 3.31 & 1.78 & 1 & 5 & 2.24 & 1.73 & 1.07 \\
Curr. Skill & 1 & 3 & 2.57 & 0.461 & 1 & 3 & 1.84 & 0.326 & 0.73 \\
Manger Tr. & 1 & 3 & 2.72 & 0.313 & 1 & 3 & 1.95 & 0.299 & 0.77 \\
Emp. Tr. & 1 & 3 & 2.51 & 0.552 & 1 & 3 & 1.82 & 0.329 & 0.69 \\
Time spent & 1 & 4 & 3.35 & 0.331 & 1 & 4 & 3.07 & 0.450 & 0.28 \\
\hline
\end{tabular}

\subsection{Estimation Strategy}

In order to investigate the impact of the CPEC-fostered tourism on MSEs performance, this study expects the CPEC is an opportunity for micro-enterprises if certain challenges are tackled timely and properly. As the purpose here is to evaluate the short and long-run impact of economic mega projects on micro and small firms, the current study uses a logistic regression estimation technique to capture the firm's performance. According to Baldwin [53], the growth of MSEs depends on various interrelated factors. To investigate these factors, the study uses binary logistic regression at the first stage. These models are usually used to approximate the mathematical relationship between the independent and dichotomous dependent variables. The said model is selected because predicting the probability of whether an event occurs or not is the nature of the dependent variable, which is categorical having only two outcomes - either firms are 'Growing' or 'Not-Growing', with a value of 1 and 0 , respectively. When the nature of the dependent variable is dichotomous, two important techniques can be used; discriminant analysis and logistic regression. However, the current study prefers logistic regression because of its advantages over discriminant analysis in terms of fewer assumptions.

Furthermore, 'Ordinary Least Squares 'OLS estimation is also discouraged under such situations because it gives biased and inefficient estimates; hence, hypothesis testing and construction of confidence intervals lead to inaccurate and misleading results. Similarly, the results generated by the linear probability model may be outside $0-1$, which is against the assumption of probability. That may cause the problem of nonnormality and heteroscedasticity. To alleviate the problem of nonnormality and heteroscedasticity, the cumulative distribution function $(\mathrm{CDFs})$ is used to represent a dichotomous response model of logit and probit. Both models yield similar results, but for mathematical simplicity, the study prefers to use logit regression because of the meaningful interpretations of odds ratios.

Odd ratios are central in logistic regression, as is the correlation coefficient in linear regression. The difference is that the null value of odd ration is 1 while the correlation coefficient is 0 . If the association is positive between dependent and independent variables, the coefficient correlation increases from 0 to 1 , and the odds ratio increases from 1 to infinity and vice versa in the case of negative association.

The simple logit model has the form

$$
\operatorname{logit}(Y)=\text { natural } \log (\text { odds })=\ln \left(\frac{\pi}{1-\pi}\right)=\alpha+\beta X
$$

In Equation (1), $\pi$ shows the probability of occurrence of an 'event' while $1-\pi$ shows the probability of nonoccurrence of the same event. In this analysis, 'event' is the growth status of firms. Taking the antilog of Equation (1) on both sides, we can derive the predicted probability of an event occurrence, i.e., predicted probability that firms will grow.

As, $\pi=$ probabilities $(Y=$ outcome of firm growthX $=x i$,

$$
\text { a spacific values of } X=\frac{e^{\alpha+\beta X}}{1+e^{\alpha+\beta X}}
$$


where $\pi$ is the probability of the outcome of the growth of firms, such as status of the firm's growth is positive/growing, $\alpha$ is the intercept of $Y, \beta$ is the regression coefficients, and $e=2.71828$ is the base of the system of natural logarithms. $X$ can be categorical or continuous, but $Y$ must always be categorical. According to Equation (1), the relationship between $X$ and $Y$ is linear, but in the case of Equation (2), the relationship is non-linear. That is why the natural log transformation of the odds in Equation (1) is necessary to make the relationship between a categorical outcome variable and its predictor(s) linear. The logit model of current study employs that,

$$
Y_{i}=\beta X+\varepsilon \mathrm{i}
$$

$Y i$ is the dependent variable representing the non-growing and growing status of micro-enterprises. The vector $X$ is representing the regressors that are characteristics of firms, perceived opportunities, and challenges of MSEs right after the CPEC project and some external factors. $\beta$ is the corresponding vector of parameters that shows the impact of independent variables, while $\varepsilon i$ is a random error term that is assumed to be logistically distributed with a mean of zero and constant variance $\varepsilon \dot{i} \sim \operatorname{IN}(0, \delta)$. We categorized the firms' growth status by considering the change in employees in the firm, such as if a firm has witnessed an increase in its workers during the start and current period, we label it growing and coded it 1 . While in the case of constant/decreased employees, we consider that firm is not growing and assigned the value 0 to it. Expanding Equation (3), where the vector $\mathrm{X}$ contains major regressors, the final model of the study employs:

$$
\ln \left(\frac{\mathrm{P}(\mathrm{Y}=1)}{\mathrm{P}(\mathrm{Y}=1)}\right)=\alpha+\beta 1 i(O P P)+\beta 2 i(C H L)+\beta 3 i(G B P)+\beta 4 i(G E)+\beta 5 i(D P)+\varepsilon i
$$

where $\alpha$ is the intercept, $\beta i$ 's show the coefficients of variables, OPP stands for 'Opportunity', which contains major variables related to the CPEC as an opportunity for micro-enterprises, while CHL stands for 'Challenge', which contains important variables that are perceived to be challenges for micro-enterprises. GBP stands for 'General Business' perception; GE stands for 'Gender Enterprises'. The study also investigates if the CPEC is an opportunity for female-owned enterprises, and DP is the demographic profile of entrepreneurs and businesses. The subscript $i$ with coefficient shows the ith firm, and $\varepsilon$ i is random error term.

This model can also be presented multiplicatively by using the exponential form in both sides where the odds ratio will be incorporated, hence Odds (growth) $=\frac{\pi}{1-\pi}=\exp (\alpha+\beta X)=e^{\varepsilon} e^{\beta i X i}$. In this form, Odds will change in multiplicative form with X. So, the interpretation of logarithm of odds is not an easy task; therefore, it can be presented in terms of probabilities.

$$
\pi=\mathrm{P}(\mathrm{Y}=1)=\exp \{\alpha+\beta i X i / 1+\exp (\alpha+\beta i X i)\} \text { or odds } / 1+\text { odds }
$$

$\ln ($ Odds $)=\ln \left(\frac{\pi}{1-\pi}\right)=\alpha+\beta X$, where $\pi$ shows the predicted probability of the event, which indicates the firm status as 'growing' and coded 1 . While $1-\pi$ is the predicted probability of firms' survival and coded 0 . The $X$ variable contains predictors that can be categorical or continuous, but in the logistic regression, variable $Y$ must be categorical, having binary outcome values growing or non-growing (1 and 0). According to Wright (1995), logistic regression is the best tool that can regress the effects of (continuous and categorical) independent variables on the categorical dependent variables.

\subsubsection{Dependent Variable}

The dependent variable is dichotomous with two outcomes; whether the $i^{\text {th }}$ firm is Growing or Non-Growing and coded as 1 and 0 , respectively. The study considers change in employees within the ith firm (Current-Initial) as a benchmark for the 'growth status' of the firm. To follow this, if the ith firm witnesses positive change in terms of employees, we consider the firm is growing and coded it 
as 1 . While on the other hand, firms witnessing no change or negative change in terms of employees are considered as 'non-growing' and coded as 0.

\subsubsection{Independent Variables}

The study estimates two different models; the first model considers both opportunities and challenges for firms due to the CPEC. The second model also incorporates female enterprises and general businesses. Tables 6-9 present the independent variables of the study and their construction strategy.

Table 6. 'Opportunity' components of the China-Pakistan Economic Corridor (CPEC).

\begin{tabular}{cccc}
\hline Variables & Component & Construction & Scale \\
\hline It strengthens tourism-related MSEs. & Opportunity1 & Based on four questions & Five-point Likert scale \\
\hline $\begin{array}{c}\text { It is increasing the level of product } \\
\text { demand from MSEs. }\end{array}$ & Opportunity2 & Based on four questions & Five-point Likert scale \\
\hline $\begin{array}{c}\text { It makes it easier to do business, } \\
\text { so labor demand increased. }\end{array}$ & Opportunity3 & Based on two questions & Five-point Likert scale \\
\hline It increases the level of sales and profit. & Opportunity4 & Based on one question & Five-point Likert scale \\
\hline
\end{tabular}

Table 7. Challenges for MSEs.

\begin{tabular}{cccc}
\hline Variables & Component & Construction & Scale \\
\hline $\begin{array}{c}\text { Quality, Cost, and Variety preferences and } \\
\text { Competition Challenge }\end{array}$ & Challenge1 & Based on five questions & Five-point Likert scale \\
\hline Challenge of Quality Management & Challenge2 & Based on two questions & Five-point Likert scale \\
\hline Challenge of Proper Planning & Challenge3 & Based on two questions & Five-point Likert scale \\
\hline Challenge of Financial Constraints & Challenge4 & Based on two questions & Five-point Likert scale \\
\hline Competition within MSEs and other firms & Challenge5 & Based on two questions & Five-point Likert scale \\
\hline Loaning facility and work burden & Challenge6 & Based on two questions & Five-point Likert scale \\
\hline
\end{tabular}

Hypothesis 1. Based on the above components, the CPEC provides enormous opportunities for MSEs, if the said challenges are addressed properly.

Table 8. General business perception of entrepreneurs.

\begin{tabular}{cccc}
\hline Variables & Component & Construction & Scale \\
\hline $\begin{array}{c}\text { Opportunities for medium and } \\
\text { large firms }\end{array}$ & gbp1 & Based on three questions & Five-point Likert scale \\
\hline $\begin{array}{c}\text { Large firm's domination/ease of } \\
\text { doing business }\end{array}$ & gbp2 & Based on two questions & Five-point Likert scale \\
\hline
\end{tabular}

Hypothesis 2. The CPEC offers remarkable opportunities for firms other than MSEs.

Table 9. CPEC and female-owned MSEs.

\begin{tabular}{cccc}
\hline Variables & Component & Construction & Scale \\
\hline $\begin{array}{c}\text { Opportunities, scope, influence, and role of } \\
\text { female-owned MSEs in the context of CPEC }\end{array}$ & foe1 & Based on six questions & Five-point Likert scale \\
\hline $\begin{array}{c}\text { CPEC-fostered tourism as a source of } \\
\text { motivation for female-owned enterprises }\end{array}$ & foe2 & Based on four questions & Five-point Likert scale \\
\hline
\end{tabular}

Hypothesis 3. The CPEC provides opportunities for female-owned enterprises.

Variables presented in Tables 6-9 are components constructed by using a five-point Likert scale from strongly disagree to strongly agree ( 1 for strongly disagree and 5 for strongly agree). Besides that, 
some other important demographic variables have also been included in empirical investigation, for example, the location of a firm, age of the firm, age of the entrepreneur, education of entrepreneur, sect, following the tradition from existing literature. 'CPEC Route' is a binary variable taking the value of 1 if the business is along the alignment of the CPEC route.

\section{Results and Discussion}

To obtain the information on the growth status of MSEs, we acquired the data on the firm's sale, profit, capital, employment, and total time spent in the businesses. The current study uses the difference of size of employees of a firm as an objective measure of firm growth status, which is computed by the change in employment between two time periods. Growth Status $=[E M P c-E M P p]$. EMPp means the size of workers in the firm when it was started, and EMPc means the size or current workers in the firm. Table 10 presents the descriptive statistics on the growth status of firms.

Table 10. Growth status of firm used as the dependent variable.

\begin{tabular}{ccccccc}
\hline Firms Performance & \multicolumn{2}{c}{ Employment } & \multicolumn{2}{c}{ Sales } & \multicolumn{2}{c}{ Profit } \\
\hline Growth Status & Number & \%Age & Number & \%Age & Number & \%Age \\
\hline Growing (1) & 114 & 40.7 & 161 & 57.5 & 210 & 75 \\
Non-Growing (0) & 166 & 59.3 & 119 & 42.5 & 70 & 25 \\
Total & 280 & 100 & 280 & 100 & 280 & 100 \\
\hline
\end{tabular}

Table 10 illustrates the performance of firms and their growth status in terms of employment, sales, and profit. It suggests that firms witness high growth in terms of profit, while growth in employment level is less than growth in profit. The information presented in these tables is consistent with many research studies that have used employment growth as a dependent variable. It means if an employer has hired an additional employee within the last one and half years, the firm is considered to be 'growing'; otherwise, it is not. Hence, the existing study estimates the binary logistic regression by taking the employment growth status as a dependent variable. According to the study, out of 280 firms, $166(59 \%)$ firms are not growing while $114(41 \%)$ firms are growing.

\subsection{Estimates of Growth Status of MSEs}

Table 11 presents the estimation results of the binary logistic regression model with firms' 'growth status' as a dependent variable. The regression includes various components of the 'opportunity' and 'challenges,' which are explained in Tables 6 and 7, respectively. The results are concerned with Hypothesis 1 . The model was constructed by the iterative maximum likelihood procedure.

Logistic regression predicts the logit of an event outcome from a set of predictors. Through the Wald chi-square statistic, the statistical significance of the regression coefficients (i.e., $\beta$ s) is tested. According to the results, four variables/components are significant predictors. Among them, the components opportunity 1 , challenge4, and challenge 5 are significant at a 5\% significance level, while the component challenge 1 is significant at $10 \%$. Except these, all other variables remained insignificant in the model. In addition, we have reported the test of Goodness of Fit (Hosmer Lemeshow) and values of Nagelkerke $\mathrm{R}^{2}$ and Cox and Snell R Square. According to the test, the model (Hosmer-Lemeshow) chi-square is 4.29 and $p>0.05$, which shows that the model fits the data well. In other words, the null hypothesis is accepted. Furthermore, the Nagelkerke $\mathrm{R}^{2}$ value has nearly the same definition as OLS $\mathrm{R}^{2}$ in linear regression. That shows the proportion of the variation in the dependent variable that can be explained by predictors in the model. In this case, variation in the model is explained by $22 \%$. 
Table 11. Binary logistic regressions-I.

\begin{tabular}{|c|c|c|c|c|c|c|c|c|}
\hline \multirow{2}{*}{ Predictors } & \multirow{2}{*}{ B } & \multirow{2}{*}{ S.E $(\beta)$} & \multirow{2}{*}{ Wald $x^{2}$} & \multirow{2}{*}{ df } & \multirow{2}{*}{$\mathbf{P}$} & \multirow{2}{*}{$\operatorname{Exp}(\beta)$} & \multicolumn{2}{|c|}{ 95\% C.I. for $\operatorname{EXP}(B)$} \\
\hline & & & & & & & Lower & Upper \\
\hline opportunity1 & 0.214 & 0.078 & 7.563 & 1 & 0.006 & 1.239 & 1.064 & 1.444 \\
\hline opportunity2 & -0.062 & 0.061 & 1.047 & 1 & 0.306 & 0.939 & 0.834 & 1.059 \\
\hline opportunity3 & -0.008 & 0.103 & 0.007 & 1 & 0.935 & 0.992 & 0.810 & 1.214 \\
\hline opportunity 4 & -0.152 & 0.106 & 2.077 & 1 & 0.150 & 0.859 & 0.698 & 1.056 \\
\hline challenge1 & 0.177 & 0.100 & 3.127 & 1 & 0.077 & 1.193 & 0.981 & 1.451 \\
\hline challenge2 & -0.011 & 0.126 & 0.008 & 1 & 0.930 & 0.989 & 0.773 & 1.265 \\
\hline challenge3 & 0.085 & 0.097 & 0.758 & 1 & 0.384 & 1.088 & 0.899 & 1.317 \\
\hline challenge4 & -0.336 & 0.117 & 8.248 & 1 & 0.004 & 0.715 & 0.568 & 0.899 \\
\hline challenge5 & 0.212 & 0.105 & 4.049 & 1 & 0.044 & 1.236 & 1.006 & 1.520 \\
\hline challenge6 & -0.046 & 0.118 & 0.155 & 1 & 0.694 & 0.955 & 0.757 & 1.203 \\
\hline marital status & -0.105 & 0.295 & 0.128 & 1 & 0.721 & 0.900 & 0.505 & 1.603 \\
\hline Education & 0.030 & 0.083 & 0.134 & 1 & 0.714 & 1.031 & 0.877 & 1.212 \\
\hline Enterprise age & 0.023 & 0.080 & 0.080 & 1 & 0.777 & 1.023 & 0.874 & 1.198 \\
\hline $\mathrm{CPEC}$ route & -0.188 & 0.389 & 0.234 & 1 & 0.629 & 0.829 & 0.387 & 1.776 \\
\hline Sect & 0.157 & 0.189 & 0.693 & 1 & 0.405 & 1.170 & 0.808 & 1.694 \\
\hline Constant & -3.119 & 1.577 & 3.911 & 1 & 0.048 & 0.044 & & \\
\hline Test/summary & & & $x^{2}$ & $d f$ & $P$ & $\mathrm{~N}-\mathrm{R}^{2}$ & C\&S-R ${ }^{2}$ & \\
\hline $\begin{array}{l}\text { Hosm-Lemeshow } \\
\text { Model summary }\end{array}$ & & & 4.249 & 8 & 0.834 & 0.221 & 0.164 & \\
\hline
\end{tabular}

The interpretation of the odds ratio gives us the association between the categorical dependent variable and categorical or continuous regressors. In this analysis, the odds ratios of significant components in the model are predicted by $\operatorname{EXP(B).~The~odds~ratio~for~the~first~significant~component~}$ opportunity1 is 1.23. This component is based on four Likert-scale (strongly disagree-to-strongly agree) questions indicating the respondents' perception regarding the statement "the CPEC strengthens tourism-related MSEs". The 1.23 odds ratio for opportunity1 indicates that the odds of growing of firm is 1.23 times more likely for each one-point increase in the respondent's perception score from strongly disagree to strongly agree. We further better explain this odds ratio in terms of percentage as we know that the null value for logistic regression is 1 . Hence, for simplicity, we can infer from this interpretation that the firm is growing $(0.23 \times 100)=23 \%$ more with a one-point perception scale regarding the variable opportunity1.

The second significant variable of the model is challenge1, and its effect is smaller but positive. This component is constructed by five questions concerning the statement "Quality, Cost \& Variety Preferences, and Competition Challenge", which follows the same perception scale as used in opportunity1. The 1.19 odds ratio of challenge1 indicates that the odds of firm growth is increasing 1.19 times more likely with a one-point increase in the respondents' perception scale regarding challenge1. Inverting this odds ratio for easier interpretation for each one-point increase of challenge1 perception scale states that there was a 1.19 odd that the firm is growing. The result suggests that the firms are better able to manage/face the challenges of quality, cost, variety, and competition level of the market. That is why firms' growth is showing a positive rather than negative relationship.

The third significant variable of the model is challenge4-"challenge of financial constraint for firms"- based on two questions. The component is negatively associated with the firm's growth. The 0.715 odds ratio for challenge 4 shows that the odds of growth of firms reduces by $(1-0.715)=0.285$ times or growing of firms are 0.285 times less likely for each one-point increase of respondent's perception scale from strongly disagree to strongly agree. Simply, the result suggests that the financial requirement for running an ideal business is always a challenge for MSE's. The challenge4 variable highlights that if the challenge of the 'financial constraint' gets tackled properly, the potential of a firm's growth can be increased by 0.28 times or $28 \%$. Providing easy access to finance and improving micro-credit facilities for businesses on the CPEC route can convert the financial challenge into an opportunity. 
The fourth significant variable in the model is challenge5, which is the component of the respondent's perception of the statement "Competition within MSEs and other firms" because of the CPEC-fostered tourism. Two questions have been used to construct the component, while the same scale has been followed for questions like all other significant components. The 1.23 odds of for challenge 5 indicate that the odds of growing of firms are 1.23 times more likely for each one-point increase in the respondent's scale about the statement from strongly disagree to strongly agree. This result suggests that micro-enterprises are well competing within MSEs as well as competing with large firms. The challenge of 'Competition' looks in favor of MSEs growth. In terms of percentage, the competition level is $23 \%$ more likely to be promising for rapid growth of MSEs.

\subsection{Estimates of Growth Status of the Firms in the Context of the CPEC, Gender Enterprise, and Overall Business Perception}

Table 12 presents the estimated results of the coefficients of binary logistic regression of MSEs growth status in the context of the CPEC, gender enterprises, and overall business perception along with demographic variables. The model was constructed by the iterative maximum likelihood procedure. By using the firms' growth status as a dependent variable and various components of female-owned enterprises (for1, foe2) and general business perception (gbp1, gbp2) as the regressors. The statistical significance of coefficients is tested by the Wald chi square test and $p$ value. The model is estimated by using female-owned enterprise components and general business perception components on the probability of growth status of enterprises. The regression shows that two variables/components are significant where gbp 1 and gbp 2 are significant at $95 \%$ and $90 \%$ confidence intervals, respectively. Except these two, all the components, including the demographics variable, remain insignificant. All of the components in Table 12 are based on the perception of respondents (5-point Liker scale) from strongly disagree to strongly agree. Below the table, the Hosmer-Lemshow test results are provided, which show the goodness of fit statistic of the model. The chi-square is 6.816 and $p>0.05$, suggesting that the model fits well to the data. In other words, the null hypothesis of a good model fit to data was tenable. Nagelkerke $\mathrm{R}^{2}$ value has nearly the same definition as OLS $\mathrm{R}^{2}$ in linear regression, showing the proportion of the variation in the dependent variable that can be explained by predictors in the model.

Odds ratios give us the predicted probability of occurrence of an event outcome against its non-occurrence. In this model, the odds ratios of the components are predicted by EXP(B). The odds ratio for the first significant component gbp 1 is 1.15-the first component of general business perception. The component is constructed by using three questions regarding the statement, "The CPEC is an opportunity for medium and large enterprises". The 1.15 odds ratio for gbp 1 suggests that the growth of MSEs is 1.15 times more likely for each one-point increase of respondent's perception score from strongly disagree to strongly agree. It suggests that the owners of micro and small enterprises are optimistic about the role of the mega project for medium and large enterprises. The results suggest that the CPEC is an opportunity for medium and large firms as well.

The odds ratio for the second component gbp2 is 0.83 . The component is constructed by two major questions concerning the perception of the statement "Large firm's domination and ease of doing business", which is inversely associated with the growth of the firm. The 0.83 odds ratio for gbp2 indicates that the growth of the firm is $(1-0.83)=0.17$ times less likely for each one-point increase of the respondent's perception scale about the statement. Inverting this odds ratio for easier interpretation, we can infer that large and medium scale firms are dominating the business in the region given that micro and small enterprises are facing a tough time. Moreover, the results further suggest that doing business became easier for large scale firms, and that is why they are dominating over micro enterprises. As a result, MSEs are marginalizing in the tourism sector of Gilgit-Baltistan. 
Table 12. Binary logistic regressions-II.

\begin{tabular}{ccccccccc}
\hline Predictors & \multirow{2}{*}{ S.E $(\boldsymbol{\beta})$} & Wald $\boldsymbol{x}^{2}$ & df & $\boldsymbol{P}$ & \multirow{2}{*}{ Exp $(\boldsymbol{\beta})$} & \multicolumn{2}{c}{ 95\% C.I. for EXP(B) } \\
Lower & Upper \\
\hline opportunity1 & 0.214 & 0.078 & 7.563 & 1 & 0.006 & 1.239 & 1.064 & 1.444 \\
opportunity2 & -0.062 & 0.061 & 1.047 & 1 & 0.306 & 0.939 & 0.834 & 1.059 \\
opportunity3 & -0.008 & 0.103 & 0.007 & 1 & 0.935 & 0.992 & 0.810 & 1.214 \\
opportunity4 & -0.152 & 0.106 & 2.077 & 1 & 0.150 & 0.859 & 0.698 & 1.056 \\
challenge1 & 0.177 & 0.100 & 3.127 & 1 & 0.077 & 1.193 & 0.981 & 1.451 \\
challenge2 & -0.011 & 0.126 & 0.008 & 1 & 0.930 & 0.989 & 0.773 & 1.265 \\
challenge3 & 0.085 & 0.097 & 0.758 & 1 & 0.384 & 1.088 & 0.899 & 1.317 \\
challenge4 & -0.336 & 0.117 & 8.248 & 1 & 0.004 & 0.715 & 0.568 & 0.899 \\
challenge5 & 0.212 & 0.105 & 4.049 & 1 & 0.044 & 1.236 & 1.006 & 1.520 \\
challenge6 & -0.046 & 0.118 & 0.155 & 1 & 0.694 & 0.955 & 0.757 & 1.203 \\
marital status & -0.105 & 0.295 & 0.128 & 1 & 0.721 & 0.900 & 0.505 & 1.603 \\
Education & 0.030 & 0.083 & 0.134 & 1 & 0.714 & 1.031 & 0.877 & 1.212 \\
Enterprise age & 0.023 & 0.080 & 0.080 & 1 & 0.777 & 1.023 & 0.874 & 1.198 \\
CPEC route & -0.188 & 0.389 & 0.234 & 1 & 0.629 & 0.829 & 0.387 & 1.776 \\
$\quad$ Sect & 0.157 & 0.189 & 0.693 & 1 & 0.405 & 1.170 & 0.808 & 1.694 \\
Constant & -3.119 & 1.577 & 3.911 & 1 & 0.048 & 0.044 & & \\
\hline Test/summary & & & $x^{2}$ & $d f$ & $\boldsymbol{P}$ & $\mathbf{N}-\mathbf{R}^{2}$ & $\mathbf{C \& S}-\mathbf{R}^{2}$ & \\
\hline $\begin{array}{c}\text { Hosmer } \\
\text { Lemeshow }\end{array}$ & & & 4.249 & 8 & 0.834 & & & \\
Model summery & & & & & & 0.221 & 0.164 & \\
\hline
\end{tabular}

\section{Conclusions}

The study has investigated the impact of the CPEC, and especially the impact of the CPEC-fostered tourism on micro and small enterprises in northern Pakistan (Gilgit-Baltistan). The study evaluates the China-Pakistan Economic Corridor as an opportunity for tourism-related MSEs having some major perceived challenges. The study analyzes the sustainability of micro and small firms operating in GB along the alignment of the CPEC route. The sample data is collected from 280 eighty entrepreneurs using questionnaires. The data is analyzed through the econometric technique of the binary logistic regression model. The major features of the study include: 1) developing a new hypotheses concerning to the CPEC's role for tourism related MSEs; 2) considering estimation models that contain variables concerning opportunities and challenges for micro and small firms, where external and internal factors of the firm have also been considered; 3 ) analyzing the perceptions of firm owners and major characteristics of firms towards the CPEC and its future potential impacts for small, medium, and large businesses.

The major hypothesis of the study presents that after the initiation of the CPEC, micro and small enterprises in the region may expand or shut down due to some internal components and some external factors (perceived challenges). The results of the regression models reveal the acceptance or rejection of each hypothesis in the study. In the first regression, four variables remain significant out of ten. The model significantly predicts that the CPEC strengthens tourism-related enterprises. It further conveys that the enterprises are growing as they effectively manage 'quality, cost, and variety' preferences and 'competition challenge'. In addition to that, firms witness confidence in handling internal and external competition levels. The only challenge that can create hindrance in growth for MSEs is the 'financial constraint' component. Likewise, the findings suggest that the influence of the CPEC has made MSEs expand by $31 \%$ in GB. Every growth factor, i.e., sale, profit, and employment, is on an upward trajectory. Besides that, entrepreneurs perceive that after the initiation of the CPEC, doing business has become relatively easier than before. That is why the businesses are expanding and hiring additional workers in firms on the rise.

On the other hand, the study also investigates the role of the CPEC for medium and large firms. The results show that this megaproject is an opportunity for medium and large enterprises as well. Based on this result, the CPEC could be a tremendous challenge for MSEs if they could not manage themselves effectively. In addition to that, the study also shows that female participation in the tourism 
sector is very rare. Women are participating in those areas of the tourism market where the literacy level is high, while in remaining areas, women's participation is very low. On the basis of the findings of this study, we suggest that access to finance for the MSEs in the region should be made available, and the procedure for applying it should be made easier. It is recommended that the banks and financial institutions in the region should initiate specific financial products such as loans for MSEs along the alignment of the CPEC route. Likewise, as the participation of women in enterprises is very low, policies and products to encourage and promote their participation will be critical for reaping the benefits of the CPEC.

As a pilot research examining the relationship between the China-Pakistan Economic Corridor and MSEs, this research will open avenues for future researchers to rely on it as a baseline.

Author Contributions: S.B.; conceptualization, methodology, project administration, and writing-original draft. M.Q.; formal analysis, and software. L.X.; funding acquisition, supervision, witting-review and editing. K.M.A.; data-curation, methodology, validation. All authors have read and agreed to the published version of the manuscript.

Funding: The research was funded by the National Natural Science Foundation of China, project No. 51778047 and One Belt One Road Infrastructure Network, project No. 2017JBZ005.

Conflicts of Interest: The authors declare no conflicts of interest.

\section{References}

1. Korytárová, J.; Hanák, T.; Kozumplíková, L.; Špiroch, M. Contribution of socio-economic benefits to economic efficiency of large-scale infrastructure projects. In Proceedings of the 20th International Research Conference on Business, Economics and Social Sciences, IRC-2015, Istanbul, Turkey, 5-6 December 2015; pp. 1-9.

2. Oppong, M.; Owiredu, A.; Churchill, R.Q. Micro and small scale enterprises development in Ghana. J. Account. Audit. Financ. Res. 2014, 2, 84-97.

3. Kirsten, M.; Rogerson, C.M. Tourism, business linkages and small enterprise development in South Africa. Dev. South. Afr. 2002, 19, 29-59. [CrossRef]

4. Brown, F.; Hall, D.D.; Hall, D.R. Tourism in Peripheral Areas: Case Studies; Channel View Publications: Bristol, UK, 2000.

5. Jovanovic, B. Selection and the Evolution of Industry. J. Econom. Soc. 1982, 50, 649-670. [CrossRef]

6. Audretsch, D.B.; Santarelli, E.; Vivarelli, M. Start-up size and industrial dynamics: Some evidence from Italian manufacturing. Int. J. Ind. Organ. 1999, 17, 965-983. [CrossRef]

7. Tourism Department, G.o.G.B. Tourism Office Report: 2017; Government of Gilgit-Baltistan: Gilgit, Pakistan, 2017.

8. Shah, A.A.; Wu, D.D.; Korotkov, V.; Jabeen, G. Do Commercial Banks Benefited from the Belt and Road Initiative? A Three-Stage DEA-Tobit-NN Analysis. IEEE Access 2019, 7, 37936-37949. [CrossRef]

9. Saad, A.; Xinping, G.; Ijaz, M. China-Pakistan Economic Corridor and its influence on perceived economic and social goals: Implications for social policy makers. Sustainability 2019, 11, 4949. [CrossRef]

10. Menhas, R.; Mahmood, S.; Tanchangya, P.; Safdar, M.N.; Hussain, S. Sustainable Development under Belt and Road Initiative: A Case Study of China-Pakistan Economic Corridor's Socio-Economic Impact on Pakistan. Sustainability 2019, 11, 6143. [CrossRef]

11. Ali, A. China Pakistan Economic Corridor (CPEC): Prospects and challenges for regional integeration. Int. J. Soc. Sci. Humanit. Stud. 2015, 7, 1-15.

12. Chok, S.; Macbeth, J.; Warren, C. Tourism as a tool for poverty alleviation: A critical analysis of 'pro-poor tourism'and implications for sustainability. Curr. Issue. Tour. 2007, 10, 144-165. [CrossRef]

13. Bank, W. World Develpment Indicators and Global Developemnt Finance. Available online: https://databank. worldbank.org/source/world-development-indicators (accessed on 10 September 2019).

14. Mulhern, A. The SME sector in Europe: A broad perspective. J. Small Bus. Manag. 1995, 33, 83.

15. Booyens, I.; Visser, G. Tourism SMME development on the urban fringe: The case of Parys, South Africa. In Urban Forum; Springer: Berlin, Germany, 2010; pp. 367-385.

16. Mead, D.C.; Liedholm, C. The dynamics of micro and small enterprises in developing countries. World Dev. 1998, 26, 61-74. [CrossRef] 
17. Rogerson, C.M. Tracking SMME development in South Africa: Issues of finance, training and the regulatory environment. In Urban Forum; Springer: Berlin, Germany, 2010; pp. 61-81.

18. Baig, S.; Hussain, H. Do shocks have permanent or transitory effects on tourist inflow? An application of stationarity test with structural breaks: Evidence reexamined for Gilgit-Baltistan, Pakistan. Asia Pac. J. Tour. Res. 2019, 25, 120-130. [CrossRef]

19. Abbas, G.; Liu, Z.; Wasti, S.H.; Munir, U.; Abbas, M. CPEC's Utility and Concerns under OBOR Initiative: A Pakistani Industrial Perspective. Economies 2019, 7, 90. [CrossRef]

20. Ali, W.; Gang, L.; Raza, M. China-Pakistan economic corridor: Current developments and future prospect for regional integration. Int. J. Res. 2016, 3, 210-222.

21. Li, X.; Alam, K.M.; Wang, S. Trend analysis of pakistan railways based on industry life cycle theory. J. Adv. Transp. 2018. [CrossRef]

22. Bouazza, A.B.; Ardjouman, D.; Abada, O. Establishing the factors affecting the growth of small and medium-sized enterprises in Algeria. Am. Int. J. Soc. Sci. 2015, 4, 101-115.

23. Mitra, J.; Matlay, H. Thematic clustering: Connecting organizational learning in small and medium-sized businesses. Ind. High. Educ. 2000, 14, 371-385. [CrossRef]

24. Reynolds, P.; Storey, D.J.; Westhead, P. Cross-national comparisons of the variation in new firm formation rates. Reg. Stud. 1994, 28, 443-456. [CrossRef]

25. Shaw, V.N. Toward professional civility: An analysis of rejection letters front sociology departments. Am. Soci. 2000, 31, 32-43. [CrossRef]

26. Thomas, R.; Shaw, G.; Page, S. Understanding small firms in tourism: A perspective on research trends and challenges. Tour. Manag. 2011, 32, 963-976. [CrossRef]

27. Irshad, M.S. One belt and one road: Dose China-Pakistan economic corridor benefit for Pakistan's economy? J. Econ. Sus. Dev. 2015, 6. Available online: https://papers.ssrn.com/sol3/papers.cfm?abstract_id=2710352 (accessed on 23 Feburary 2020).

28. Ali, L.; Mi, J.; Shah, M.; Shah, S.J.; BiBi, K. The potential socio-economic impact of china Pakistan economic corridor. Asian Dev. Policy Rev. 2017, 5, 191-198. [CrossRef]

29. Ali, S.A.; Haider, J.; Ali, M.; Ali, S.I.; Ming, X. Emerging Tourism between Pakistan and China: Tourism Opportunities via China-Pakistan Economic Corridor. Int. Bus. Res. 2017, 10, 204-214. [CrossRef]

30. $\mathrm{Yu}, \mathrm{M}$. Research on the Impact of Infrastructure Construction on Tourism Industry: Evidence from the "Wuhan-Guangzhou High-Speed Rail". Open J. Soc. Sci. 2016, 4, 126. [CrossRef]

31. Hegarty, C.; Przezborska, L. Rural and agri-tourism as a tool for reorganising rural areas in old and new member states-a comparison study of Ireland and Poland. Int. J. Tour. Res. 2005, 7, 63-77. [CrossRef]

32. Mshenga, P.M.; Owuor, G. Opportunities for Micro and Small Scale Businesses in the Tourism Sector: The Case of The Kenya Coast Patience M. Mshenga 2. J. Bus. Manag. 2009, 2. [CrossRef]

33. Ahmad, I.; Oláh, J.; Popp, J.; Máté, D. Does business group affiliation matter for superior performance? Evidence from Pakistan. Sustainability 2018, 10, 3060. [CrossRef]

34. Hill, T.; Nel, E.; Trotter, D. Small-scale, nature-based tourism as a pro-poor development intervention: Two examples in Kwazulu-Natal, South Africa. Singap. J. Trop. Geogr. 2006, 27, 163-175. [CrossRef]

35. Joosten, M.; Marwijk, R.V. A Small Contribution?: Small Tourism Entrepreneurs and Sustainable Development in Malindi. Ph.D. Thesis, Wageningen University, Wageningen, The Netherlands, 2003.

36. Alam, K.M.; Li, X.; Baig, S. Impact of Transport Cost and Travel Time on Trade under China-Pakistan Economic Corridor (CPEC). J. Adv. Transp. 2019. [CrossRef]

37. Page, S.J.; Forer, P.; Lawton, G.R. Small business development and tourism: Terra incognita? Tour. Manag. 1999, 20, 435-459. [CrossRef]

38. Gössling, S.; Garrod, B.; Aall, C.; Hille, J.; Peeters, P. Food management in tourism: Reducing tourism's carbon 'foodprint'. Tour. Manag. 2011, 32, 534-543. [CrossRef]

39. Bolton, J.E. Report of the Committee of Inquiry on Small Firms. 1971. Available online: https://searchworks. stanford.edu/view/10069814 (accessed on 23 Feburary 2020).

40. Morrison, A.M.; Morrison, A.M. Hospitality and Travel Marketing; Cengage Learning: Boston, MA, USA, 1996.

41. Fuller, D.; Buultjens, J.; Cummings, E. Ecotourism and indigenous micro-enterprise formation in northern Australia opportunities and constraints. Tour. Manag. 2005, 26, 891-904. [CrossRef]

42. Nichter, S.; Goldmark, L. Small firm growth in developing countries. World Dev. 2009, 37, $1453-1464$. [CrossRef] 
43. Islam, M.A.; Khan, M.A.; Obaidullah, A.Z.M.; Alam, M.S. Effect of entrepreneur and firm characteristics on the business success of small and medium enterprises (SMEs) in Bangladesh. Int. J. Bus. Manag. 2011, 6, 289.

44. Akbaba, A. Understanding small tourism businesses: A perspective from Turkey. J. Hosp. Tour. Manag. 2012, 19, 31-47. [CrossRef]

45. Maleka, A.M.; Fatoki, O. The Role of Government in Developing Small, Medium and Micro Enterprises in South Africa. J. Soc. Sci. 2016, 49, 307-310. [CrossRef]

46. Ateljevic, J. Small tourism firms and management practices in New Zealand: The Centre Stage Macro Region. Tour. Manag. 2007, 28, 307-316. [CrossRef]

47. McPherson, M.A. Growth of micro and small enterprises in southern Africa. J. Dev. Econ. 1996, 48, $253-277$. [CrossRef]

48. Haber, S.; Reichel, A. Identifying performance measures of small ventures-the case of the tourism industry. J. Small Bus. Manag. 2005, 43, 257-286. [CrossRef]

49. Basu, A.; Goswami, A. Determinants of South Asian entrepreneurial growth in Britain: A multivariate analysis. Small Bus. Econ. 1999, 13, 57-70. [CrossRef]

50. Chell, E. The entrepreneurial personality: A few ghosts laid to rest? Int. Small Bus. J. 1985, 3, 43-54. [CrossRef]

51. Glancey, K. Determinants of growth and profitability in small entrepreneurial firms. Int. J. Entrep. Behav. Res. 1998, 4, 18-27. [CrossRef]

52. Smith, N.R.; Miner, J.B. Type of entrepreneur, type of firm, and managerial motivation: Implications for organizational life cycle theory. Strateg. Manag. J. 1983, 4, 325-340. [CrossRef]

53. Baldwin, J.; Picot, G. Employment generation by small producers in the Canadian manufacturing sector. Small Bus. Econ. 1995, 7, 317-331. [CrossRef]

(C) 2020 by the authors. Licensee MDPI, Basel, Switzerland. This article is an open access article distributed under the terms and conditions of the Creative Commons Attribution (CC BY) license (http://creativecommons.org/licenses/by/4.0/). 